\title{
Characteristics Of Domestic Violence Wound In R. M. Djoelham Binjai General Hospital In 2019-2020
}

\author{
Ibnu Arizona Siregar, Agustinus Sitepu, Aulia Siregar \\ Department of Forensic and Medicolegal, Faculty of Medicine University of North Sumatera \\ DOI: 10.29322/IJSRP.11.11.2021.p11952 \\ http://dx.doi.org/10.29322/IJSRP.11.11.2021.p11952
}

\begin{abstract}
Domestic violence is a universal incident that can occur regardless of age, profession, economic and education level of the victims. Domestic violence is an abuse to a person, mostly woman, by her husband, which resulted in misery, physical, sexual, physical pain, or neglection including threatening, forcing, or taking away independent will of the victim against the law in prior to household. Doctors are obliged to be able to clarify the type of wound, location of the wound in the victim's body, and the wound degree qualification. This is an observational study with descriptive design using a retrospective approach. This study was conducted in R. M. Djoelham Binjai General Hospital, the samples were the result of Visum et Repertum examination from victims of domestic violence from 2019 to 2020 . From the $1^{\text {st of } J a n u a r y ~} 2019$ to the $31^{\text {st }}$ of December 2012, woman $(97.5 \%)$ is the most reported victims in domestic violence, there were more than one types of wounds $(68.3 \%)$ and more than one location of the wound $(63.4 \%)$. The most common site of the wound was head (28 cases). Most of the victims were having a blunt trauma (79\%), the most types of wounds found was bruise $(44.7 \%)$ and the most reported wound degree was moderate degree $(48.7 \%)$.
\end{abstract}

Index Terms- Characteristic of wound, domestic violence, Binjai City

\section{BACKGROND}

$\mathrm{D}$ omestic violence cases increase every year. Domestic violence is a universal incidence that can occur regardless of the victim's age, profession, economic or education level.

Domestic violence is an abuse to a person, mostly woman, by her husband, which resulted in misery, physical, sexual, physical pain, or neglection including threatening, forcing, or taking away independent will of the victim against the law in prior to household.

Based on the data from Simfoni Mother and Child protection, the number of domestic violence incidents from 2019 to February 2020 in North Sumatera province were 260 cases, in which, domestic violence against woman according to their age groups were respectively 76 cases for women between 28 to 25 years old and 184 cases for woman higher than 25 years old, according to their profession, 126 cases were housewives, and the most common type of violence reported were physical abuse, reported in 149 cases, in Binjai City, in 2019 there has been 15 reports of domestic violence. There has not been a prior study about the type of violence, location of the wound in the victim's body and wound degree classification. Based on this background, the author aims to conduct this study.

\section{METHOD}

This is an observational study with descriptive design using the retrospective approach using the data from the result of Visum et Repertum examination. This study was conducted from July 2021 to October 2021 in the department of Forensic in R. M. Djoelham General Hospital, Binjai City.

The samples in this study were all result of forensic examination (total sampling) in the form of Visum et Repertum report of the victims of domestic violence in Binjai city from 20192020 under several criteria of inclusion and exclusion. The subject of this study must match the criteria of inclusion and exclusion. The criteria of inclusion this study was the Visum et Repertum report of living victims of domestic violence in R. M. Djoelham General Hospital Binjai from the $1^{\text {st }}$ of January until the $31^{\text {st }}$ of December 2020. The criteria of exclusion for this study were Visum et Repertum of psychological violence, household neglection and traffic accidence.

The collected data was analyzed according to each variables using the SPSS software. The data will be analyzed using univariate analysis to determine the frequency of the distribution of each variable. The result will be shown in tables and figures based on each category.

\section{RESULT AND DISCUSSION}

There were 44 reports of Visum et Repertum reported in R. M. Djoelham General Hospital Binjai, however only 41 of these reports match the criteria of inclusion. There were 3 reports that didn't match the criteria of inclusion due to several factors; the conclusion of the Visum et Repertum was no sign of violence (2 reports), and violence performed by the son of the first wife of the husband which was not counted as household member (1 report).

The characteristic of the samples in this study were shown based on the frequency of the distribution based on sex in Table 1. 
Table 1. Characteristic of samples.

\begin{tabular}{llll}
\hline Characteristic & Note & N & \% \\
\hline Sex & Female & 40 & 97.5 \\
& Male & 1 & 2.5 \\
\hline
\end{tabular}

The result of this study showed that the most victims were woman $(97.5 \%)$. The reports from various study always showed that most of the victims of a domestic violence were woman. Gender issue, patriarchy socio-cultural culture, the level of economic dependency of woman, and the low level of education of the community were the factors that contribute for woman becoming the most common victims for domestic violence.

The study about characteristic oof wounds were divided into 4 parts, the number of wounds, location of the wound, type of violence and wound degree, which can be seen in Table 2.

Table 2. Characteristic of wound in domestic violence cases

\begin{tabular}{llll}
\hline Variables & & $\mathbf{N}$ & $\%$ \\
\hline $\begin{array}{l}\text { Number of } \\
\text { wounds }\end{array}$ & One & 13 & $31.7 \%$ \\
& More than One & 28 & $68.3 \%$ \\
\hline Location & One & 15 & $36.6 \%$ \\
& More than one & 26 & $63.4 \%$ \\
\hline $\begin{array}{l}\text { Type of } \\
\text { Wound }\end{array}$ & Mechanic & 38 & $92.6 \%$ \\
& Physical & 2 & $4.9 \%$ \\
& Chemical & 1 & $2.5 \%$ \\
\hline Wound & Mild & 16 & $39.1 \%$ \\
Degree & Moderate & 20 & $48.7 \%$ \\
& Severe & 5 & $12.2 \%$ \\
\hline
\end{tabular}

The result of the characteristic of wound based on the number of wounds showed that most of the domestic violence causes more than one wound for the victims (28 cases; $63.8 \%$ ) compared to only one wound (13 cases; $31.7 \%$ ). This showed that the victims of domestic violence often experienced repeated violence with several types of violence in different body region.

From the result of this study, it was shown that most of the wound were in more than one location (26 cases; 63.4\%). The wounds were found in several different region such as head, neck, chest, abdomen, back, bottom, upper extremities, and lower extremities.

This study showed that the most common site of the wound in domestic violence was head, which were 28 cases, followed by upper extremities and lower extremities. This result was similar with the result of prior study by Emmanuela R. Moleenar et al., which showed that temporal, occipital and frontal region of head and also eye were the most common site of the wound.
Figure 1. Location of the wounds in domestic violence cases.

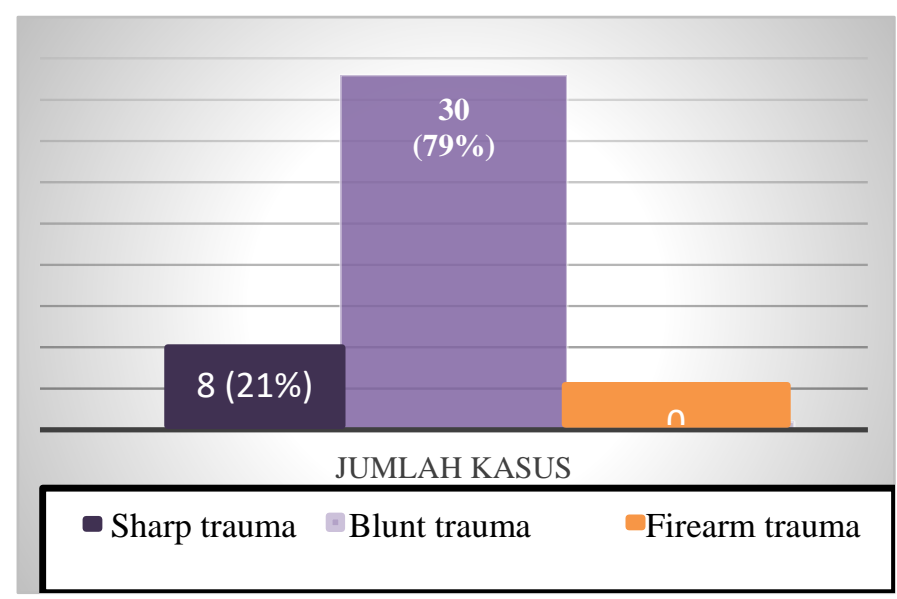

There were several types of violence, mechanical violence, physical violence, and chemical violence. In this study, the most common type found was mechanical violence which were 38 cases $(92.6 \%)$. Wound caused by mechanical trauma can be differentiated based on its cause, which were blunt trauma for 30 cases $(79 \%)$ sharp object trauma for 8 cases $(21 \%)$, and firearm trauma for 0 cases.

This result was similar with the result of prior study by Jefryanto et al., which showed that the most common type of violence experience by the victims was mechanical trauma caused by blunt trauma which were 150 Visum et Repertum (94.9\%) from 158 reports.

Figure 2. The type of mechanical trauma in domestic violence trauma

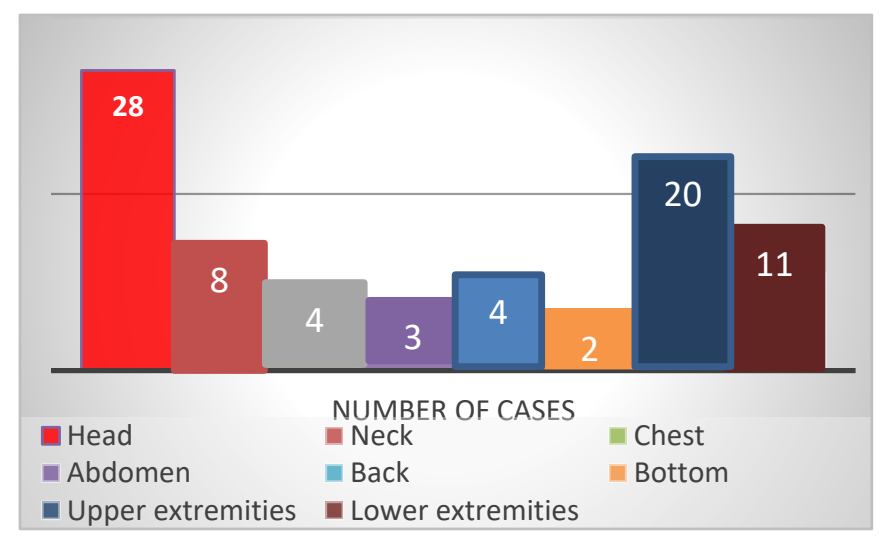

According to KUHP, the type of wound can be classified into 3 classes which were mild degree, moderate degree, and severe degree. In this study, the highest number of cases were moderate wound degree which were 20 cases (48.7\%), followed by mild degree for 16 cases (39.1\%), and severe degree for 5 cases $(12.2 \%)$. This result might be due to the background of the domestic violence incidence which were to give a lesson through punishment, not to create a life-threatening wound. 


\section{CONCLUSIN AND SUGGESTION}

Based on the result of this study which was conducted in R. M. Djoelham General Hospital Binjai about the characteristic of wound in domestic violence cases from 2019-2020. We can conclude that the victims were mostly female, with more than one wound, mostly around the head region with the most common type of wound found was bruise, the most common wound degree in this study was moderate wound degree.

This study used total sampling method with 41 samples in 2 years period. The number of samples in this study was minimal. For the coming study, we suggest that a larger number of samples can be used to give a better picture of this condition.

\section{AUTHORS}

First Author - Ibnu Arizona Siregar, Department of Forensic and Medicolegal, Faculty of Medicine University of North Sumatera, Email: ari.zona11.az@gmail.com

Second Author - Agustinus Sitepu, Department of Forensic and Medicolegal, Faculty of Medicine University of North Sumatera Third Author - Aulia Siregar, Department of Forensic and Medicolegal, Faculty of Medicine University of North Sumatera 